$7-21-2020$

\title{
The Logic Model, Participatory Evaluation and Out of School Art Programs
}

Kimberly A. Kleinhans

Wayne State University, kleinhak@gmail.com

Follow this and additional works at: https://digitalcommons.wayne.edu/jmasm

Part of the Applied Statistics Commons, Social and Behavioral Sciences Commons, and the Statistical Theory Commons

\section{Recommended Citation}

Kleinhans, K. A. (2019). The Logic Model, Participatory Evaluation and Out of School Art Programs. Journal of Modern Applied Statistical Methods, 18(2), eP3284. https://doi.org/10.22237/jmasm/ 1604190540

This Quantitative Program Evaluation is brought to you for free and open access by the Open Access Journals at DigitalCommons@WayneState. It has been accepted for inclusion in Journal of Modern Applied Statistical Methods by an authorized editor of DigitalCommons@WayneState. 


\title{
SPECIAL SECTION ON QUANTITATIVE PROGRAM EVALUATION \\ The Logic Model, Participatory Evaluation and Out Of School Art Programs
}

\author{
Kimberly A. Kleinhans \\ Wayne State University \\ Detroit, MI
}

The logic model and participatory evaluation are two popular methods of conducting program evaluation. Although both methods have their strengths, each has distinct weaknesses which can be ameliorated by combining them both together. The combined method is used to evaluate an out of school art program at a museum. Using both the logic model and participatory evaluation yielded beneficial results with more accurate representation of program outcomes.

Keywords: logic model, participatory evaluation, art education, out of school art programs, retrospective pretest-posttest design, Wilcoxon signed-rank test

\section{Introduction}

A popular quantitative program evaluation approach is the logic model approach. According to Renger and Titcomb (2002), "a logic model is a visual representation of a plausible and sensible model of how a program will work under certain conditions to solve fundamental problems and is fundamental to program evaluation" (p. 493). Cooksy, Gill, and Kelly (2001) stated the evaluator begins the assessment of the ability to evaluate through establishing the logic model from information found in program materials and by talking to the managers of the program. The next step they outline is for the evaluator to use the knowledge they have gleaned from the materials and interviews in a depiction which is "a simple flow chart that outlines the needed resources, intended activities, expected outputs, and desired outcomes" (p. 120). Figure 1 is an example of a logic model. It lists

doi: 10.22237/jmasm/1604190540 | Accepted: Jul 30, 2019; Published: July 21, 2020.

Correspondence: Kimberly A. Kleinhans, kleinhak@gmail.com 


\section{KIMBERLY A. KLEINHANS}

resources, activities, outputs and outcomes of an imaginary outdoor education program.

\begin{tabular}{|c|c|c|c|}
\hline Resources & Activities & Outputs & Outcomes \\
\hline $\begin{array}{l}\text { - Canoes } \\
\text { - Volunteers }\end{array}$ & Canoe trips & $\begin{array}{l}-3-4 \text { trips/week } \\
-3-6 \text { visitors/trip }\end{array}$ & $\begin{array}{l}10 \% \text { increase in the use of native } \\
\text { plant species in residential } \\
\text { landscapes by } 2002\end{array}$ \\
\hline
\end{tabular}

Figure 1. Logic Model (Cooksy, Gill \& Kelly, 2001)

By 1998, the United Way was promoting the use of the logic model, stating, "A program logic model is a description of how the program theoretically works to achieve benefits for participants" (United Way of America, 1998, p. 38). McLaughlin and Jordan (1999) observed "Evaluators have found the Logic Model process useful for at least twenty years" (p. 66).

The popularity of the logic model grew, and eventually the W. K. Kellogg Foundation recommended the use of the model for its grantees. Their staff authored a guide as a resource for grantees and others (W. K. Kellogg Foundation, 2004). In the guide, the logic model was described as being "a systematic and visual way to present and share your understanding of the relationships among the resources you have to operate your program, the activities you plan to do, and the changes or results you hope to achieve" (W. K. Kellogg Foundation, 2004, p. 1).

Despite the popularity of using the logic model in program evaluation, weaknesses of this model abound. Its use is limited when programs are too complex to fit in a simple model: "When evaluators build logic models and indicators, we often are doing our best to simplify complex arenas, which at best allows us to revise the tools we generate, but can also have its risks... trying to force simple frameworks on complex arenas" (Fiero, 2016, p. 37).

Environmental factors surrounding a program pose strategic issues. "[T]he social climates of programs and contexts in which they operate also contribute to outcomes, but are difficult, if not impossible, to capture in logic models." (Isaacs, Perlman \& Pleydon, 2004, p. 515). Related to those factors, "Logic models are useful for structuring evaluation, but are limited in scope. A more complete understanding of outcomes requires that factors outside this scope be included in program evaluation" (Isaacs, Perlman \& Pleydon, 2004, p. 515). Another weakness of logic model use in program evaluation was detailed by Kaplan and Garrett (2005), who opined the distinction between outputs and outcomes was not clear, 


\section{THE LOGIC MODEL AND ART PROGRAMS}

and there may be "resistance of those who may feel that the logic model exercise is a distraction from the true work of program implementation, or who are intimidated by its jargon" (p. 171). Cooksy, Gill and Kelly (2001) stated "Another concern is that a logic model can become a rigid statement of the program's plan and thereby limit the program's responsiveness to new information" (p. 121). Unintended effects are often ignored. For example, Cooksy, Gill and Kelley (2001) noted, "Program evaluators may use the logic model inflexibly, assuming that compliance with the model is a measure of the quality of the program and ignoring unintended effects that are not part of the program theory" (p. 121).

\section{Participatory Evaluation}

Another common type of program evaluation is participatory evaluation. In participatory evaluation, there is collaboration between those doing the evaluation, and program stakeholders (Cousins \& Whitmore, 1998). Boody (2009) stated a participatory evaluation happens when the person doing the evaluation "does not distance herself from the program and its participants," rather, she engages in an active way with the stakeholders (p. 49).

An advantage of participatory evaluation is there is an increased likelihood of the evaluation findings being used to improve the program quality. According to Cousins and Whitmore (1998), participatory evaluation methods result in greater utilization of results while maintaining "technical quality" (p. 7). Similarly, Brisolara (1998) noted a benefit to participatory evaluation is, in addition to an increase in utilization, more diversity of ideas from stakeholders who might otherwise be marginalized. Brisolara (1998) also stated a participatory evaluation "promotes inclusiveness" (p. 26), and situates "program evaluations within their social contexts and [responds] to the needs manifested in those contexts" (p. 27).

Another advantage of participatory evaluation is it elevates the experience of those being evaluated. Boody (2009) explained "[o]ne reason for including program participants in the evaluation of their program is to overcome the evaluation anxiety or resentment that afflicts many evaluees" (p. 48). King (1998) agreed, adding participatory methods can make the experience of the evaluation easier, provide answers to questions regarding the program, gain data from primary sources, and provide a learning experience.

However, the weaknesses of participatory evaluation are as numerous as the logic model. A key weakness of participatory evaluation is evaluator bias and lack of objectivity (Brisolara, 1998). It is a common perception an evaluator should be outside the program being assessed, remain somewhat removed to maintain 


\section{KIMBERLY A. KLEINHANS}

impartiality, and have vast knowledge and appropriate education (Boody, 2009). There are "concerns with objectivity" when evaluators proceed with processes which are "a more active stance with a program" (Boody, 2009, p. 50).

Another weakness of participatory evaluation is the lack of technical quality (Whitmore, 1998). Further, sometimes there is manipulation of data by participants (Cousins \& Whitmore, 1998). Other problems with participatory evaluation are uncritical acceptance of what the participants do and say (Boody, 2009), response bias in participants (Jardine \& James, 2012), all participants not being represented, with some participants being over-involved in comparison to their peers (Powers \& Tiffany, 2006), and lack of human subjects protocol training (Powers \& Tiffany, 2006).

It is possible to ameliorate the weaknesses of both the logic model and participatory evaluation by combining their specific strong elements. For example, the logic model's weakness of not considering social contexts of a program (Isaacs, Perlman \& Pleydon, 2004) can be improved by including participatory methods, which have an element of situating the evaluation within a social context (Brisolara, 1998). Similarly, using the structure of the logic model can address the weakness of participatory evaluation of technical quality (Whitmore, 1998). Therefore, it would be more appropriate to use a mixed methods approach to evaluation which capitalizes on the strengths of both of the reviewed approaches, particularly, when it comes to a sensitive research context.

\section{Out of School Arts Programs}

According to Little, Wimer, and Weiss, (2008) different terms are used to describe out of school programs for youth, including "after school," "out of school," and "out-of-school time" (p. 3). They suggested out of school programs are a plethora of secure, organized things to do which contribute opportunities to learn for K-12 students in addition to the regular school day. Out of school time programs can foster essential circumstances which connect attendance in these programs to clearcut outcomes in the time of pre-adulthood (Greene, Lee, Constance, \& Hynes, 2012). Participants were found to have "somewhat fewer absences" for regular school attendance than a comparison group (O'Donnell, \& Kirkner, 2014, p. 176). One type of out of school program is out of school art program. Regular arts classes in schools were defunded in response to budget deficits, therefore, out of school programs are about the only way in which many school students can engage in arts educational activities. 


\section{THE LOGIC MODEL AND ART PROGRAMS}

Among the benefits of out of school art programs is these programs boost "academic achievement of at-risk youth," as well as providing a reduction in "drug use and juvenile delinquency," raising confidence, and developing specific intercommunications between others the same age or adults (Charmaraman, \& Hall, 2011 , p. 18). Another benefit is young people who strive to succeed in out of school environments "where the medium of engagement was the visual arts, including sculpture, pottery, photography, painting with both oils and watercolors, and jewelry and fashion design," discovered and became proficient in finding the importance of, questioning, and inquisitively investigating preponderant societal traditions (Vadeboncoeur, 2006, p. 252). Green and Kindseth (2011) found in out of school arts programs, creative methods are specifically appropriate for "key outcomes of personal growth and interpersonal connection" because of their combination of the exchange of ideas and important considerations in situations where there is education for groups and individuals (p. 338).

\section{Purpose of the study}

Given the known weaknesses of the two models, the logic model approach may potentially be improved by incorporating elements of participatory evaluation. In order to demonstrate the efficacy of this approach, the purpose of the current study was to synthesize the two approaches where they complement each other. A demonstration of the new model's effectiveness will be performed by evaluating an out of school arts program. The modified approach was beneficial with the addition of participatory evaluation components, because out of out of school-based youth programs are known to be amenable (Flores, 2008).

\section{Limitations}

Distinct limitations exist in this quantitative program evaluation study. One limitation is the evaluation was initiated by the researcher rather than the organization whose program is being evaluated. Another limitation was the researcher was an employee of the organization, and therefore was an internal rather than external evaluator. 


\section{KIMBERLY A. KLEINHANS}

\section{Literature Review}

\section{Logic Model}

Julian, Jones and Deyo (1995) used the logic model to evaluate two different social service programs. They described the logic model as being a reasonable sequence of assertions which connect the circumstances a program is designed to focus on, the actions undertaken to improve the circumstances, and the predicted outcomes of the actions. They said the logic model is useful for developing agreement between personnel regarding the "problems, activities and outcomes" of a program, gives a structure for a "process evaluation" (p. 335), pinpoints central hypotheses regarding the particular endeavors which lead up to distinct outcomes, and examines in contrast the program's intentions to the results which were achieved. They said a benefit of logic models is they give a chance to contemplate connections "between problems/conditions, activities, outcomes, and impacts" (p. $335)$.

The United Way of America (1996) suggested the logic model is a beneficial foundation for looking at outcomes. Another benefit they outline is the logic model assists program managers in thinking about the actions being taken for clients' development and getting a representational idea of what the program could predict in terms of client accomplishments. Additionally, they said the logic model can assist in the identification of "key program components" which should be traced in order to evaluate the performance of a program (p. 38). They gave examples of logic models, worksheets to facilitate logic model development, and instructions for creating outcomes.

McLaughlin \& Jordan (1999) recommended the logic model as an approach to satisfy evaluation obligations set forth by the Government Performance and Results Act (GPRA). Their examples of logic models in the article included "customers reached" in addition to the usual features of a logic model, with "resources, activities, outputs, customers reached, short, intermediate and longer term outcomes" as their basic building blocks for a logic model (p. 65). They listed benefits of the logic model, which included: creating a prevailing awareness, assisting in program construction and development, getting across the location of the program inside the echelons of the organization, and indicating a uniform collection of "key performance measurement points" (p. 66).

Cooksy, Gill and Kelly (2001) used the logic model to aim attention at keeping data collection pertinent to activities and outcomes, to arrange data, and to make sense of the data which came from numerous methods. They investigated "a 


\section{THE LOGIC MODEL AND ART PROGRAMS}

middle school curriculum delivery program" which had an expected outcome of computer skills (p. 119). They said logic models are flexible and there is more than one suitable logic model for any given program. They voiced some concerns about logic models in they can be expensive and might be used in too rigid of a manner. Additionally, they opined evaluators may over-stress adherence to the logic model, and thus not notice "unintended effects that are not part of the program theory" ( $p$. 121).

Renger and Titcomb (2002) came up with a three-step approach to teaching how to create a logic model. They warned against trying to fit too much information into a logic model, because the more boxes there are, the more likely the "underlying rationale" (p. 495) becomes occluded.

The W.K. Kellogg Foundation (2004) guide to developing logic models suggested a benefit of using the logic model as being a facilitator of practical program preparation, performance, and assessment. They also stated the use of the logic model can result in favorable circumstances for learning. This guide outlined the steps one would take in constructing a logic model for a program, with numerous examples, detailed worksheets, and checklists.

In their investigation of an application of the logic model, Isaacs, Perlman and Pleydon (2004) found limitations in the method. They interviewed stakeholders in a foster care program in Canada, and used the information gathered through these interviews to create a logic model. They found connections among stakeholders, perspectives regarding instruction, common obligations to foster families, and several other key aspects of the program were not easily corralled into the logic model framework. They concluded, "Logic models are useful for structuring evaluation, but are limited in scope. A more complete understanding of outcomes requires that factors outside this scope be included in program evaluation" (p. 515).

Kaplan and Garrett (2004) looked at three different programs which utilized the logic model as a grant requirement. They found the use of the logic model to encourage working together to be an organizational challenge when resources were scant, or when constituents were not centralized. In their study, they discovered another challenge in the use of the logic model occurred when there were groups working together which were vastly different, even when those who were working together were tightly knit and located near each other.

Gugiu and Rodríguez -Campos (2007) created a series of questions which can be asked by the evaluator in order to gather information to create a logic model. They said inevitably every professional evaluator will come to a time when they will have to create a logic model. Some benefits of using a logic model they listed include: helping evaluators aim their attention at the most important aspects of a 


\section{KIMBERLY A. KLEINHANS}

program, giving program personnel a simple awareness of program objectives, and determining a way to gauge success which can be used to relay information to grant makers and other stakeholders. In their view, a logic model is not a static thing, rather, a continuous process. They did, however, note the use of a logic model in a rigid manner can lead to the evaluator disregarding unplanned side effects.

Epstein and Klerman (2013) asserted the use of a logic model could be more appropriate than undertaking a rigorous impact evaluation. Their claim was a program might not be ready for a rigorous impact evaluation, and the logic model would be a less expensive way to discover the program was not a good candidate for the rigorous impact evaluation. They noted the "determination of whether a program achieves the intermediate outcomes specified by its own logic model can often be made using conventional process evaluation methods, that is, careful observation of program operation, without random assignment and without a comparison group" (p. 382). They discussed five types of logic model failure which can signal a program is not a good candidate for rigorous impact evaluation, which were: 1) "Failure to secure required inputs" (p. 383), 2) "low program enrollment" (p. 384), 3) "low program completion rates" (p. 385), 4) "low fidelity" (p. 386), and 5) "lack of pre/post improvement" (p. 387). In the cases they studied, costly rigorous impact evaluations were performed which found no impact, which could have been discovered by a logic model.

Fiero (2016) mentioned logic models in a larger discussion of the dynamic between simplification and "unveiling complexity" (p. 37). They were portrayed as being an oversimplification of complexity, which can lead to chaos.

In 2017, the W. K. Kellogg Foundation staff authored a guide to program evaluation that included the use of the logic model. They stated the benefits of the logic model include: "Using the logic model results in effective design of the effort and offers greater learning opportunities, better documentation of outcomes and shared knowledge about what works and why" (W. K. Kellogg Foundation, 2017, p. 104). They suggested the logic model is not a stand-alone evaluation methodology; rather, it is a tool which can be used as part of the program evaluation process.

\section{Participatory Evaluation Strengths and Weaknesses}

Brisolara (1998) noted a distinct limitation in participatory evaluation as being there is a potential for evaluator bias and lack of objectivity. "One of the most frequent and apparently serious charges leveled against PE [participatory evaluation] by its critics is that PE violates a long-held evaluation principle (or tradition) by forsaking 


\section{THE LOGIC MODEL AND ART PROGRAMS}

an objective-as-possible stance for what some see as an inevitable slide into the pits of relativism" (p. 34). Brisolara felt absorption into various viewpoints without any constraints to judgement can hamper evaluators in executing professionalism. Brisolara said a particular limitation of participatory evaluation is this type of evaluation is not able to detect the effects of the intervention. Brisolara noted a benefit to participatory evaluation is, in addition to an increase in utilization, there is more diversity of ideas from stakeholders who might otherwise be marginalized. Brisolara also stated participatory evaluation "promotes inclusiveness" (p. 26), and situates "program evaluations within their social contexts and [responds] to the needs manifested in those contexts" (p. 27).

Burke (1998) suggested there is not an "off-the-shelf" (p. 43) procedure for participatory evaluation. Burke outlined several of what were called the "Principles of Participatory Evaluation" (p. 43), which included: those who benefit from the program and other stakeholders needed to be included in the evaluation, the evaluation was based on the conditions of those considered to be the "end users" of the program (p. 44), stakeholders' understanding was given regard by the evaluation, and power was shared between the stakeholders and the evaluator. Burke asserted there were "key elements of the process" (p. 45), which included including the stakeholders, addressing lack of balance in authority, and the participatory evaluation increased capacity and knowledge. Burke noted participatory evaluations can be conducted by internal stakeholders with facilitation by an external evaluator. The stakeholders needed to be trained so they have an understanding of what evaluation is and how to do it. If the stakeholders were trained properly, they could be responsible for data collection.

According to Cousins and Whitmore (1998), examples of participatory evaluation can be found dating as far back as the 1940s, with a preponderance of the usages they observed occurring from the time of the 1970s. They found the description of the concept was not applied in the same manner by everyone who used it. One way it was used to describe a "practical approach" for augmenting conclusions and answering questions "through systematic inquiry" (p. 5). The other way the term was used was for a radical approach to redistribute control for the creation of knowledge, while advancing social change.

King (1998) found participatory methods can make the experience of the evaluation easier, provide answers to questions regarding the program, gain data from primary sources, and provide a learning experience. King (1998) noted several conditions which must be met in order for participatory evaluation to work. Among them, King said there must be confidence in the trustworthiness on the part of all the stakeholders involved. King (1998) also included in the conditions for successes 


\section{KIMBERLY A. KLEINHANS}

in participatory evaluation people are willing to volunteer their time and energy and there are clear leaders. Another condition King mentioned was participatory evaluation takes time. Additionally, King asserted participatory evaluations require outside facilitators to bring a different view of the program being evaluated, as well as technical skills.

Whitmore (1998) noted a limitation of participatory evaluation is "complicated statistical studies" cannot be performed by stakeholders who are not trained in advanced methods (p. 96). Whitmore stated capacity building is a beneficial outcome of participatory evaluation methods.

Turnbull (1999) described participatory evaluation as circumstances where the program stakeholders take part in the conclusions made in evaluation, as well as having responsibilities with the evaluator in creating the evaluation report. Turnbull said participatory methods boost the use of evaluation findings. Additionally, when participation of stakeholders takes place in evaluation, stakeholders have increased program comprehension and increased vested interests and inclinations to utilize the findings of the evaluation.

Boody (2009) stated historically, participatory evaluation was frowned upon because of the perception the externality of an evaluator was necessary, objectivity is best perpetuated by detachment, and specific knowledge and training were imperative. Strengths of participatory evaluation noted by Boody include surmounting the apprehension of those being evaluated, increased utilization, and egalitarian sentiments. According to Boody, these three strengths of participatory harken to the notion program participants should participate in the evaluation.

Jacob, Ouvrard, and Belanger (2011) investigated the utilization of the results of participatory evaluation in an organization which provided services to at-risk young people and families. They asserted the utilization of participatory evaluation findings was not limited to the final product, but during the implementation of the evaluation strategy, stakeholders gained insight from the process of evaluating their program. They analyzed the participation of stakeholders, "including difficulties and obstacles that restrained their participation" (p. 115). They found the impact of the participatory evaluation process was greater for the program staff (social workers) than for the clients of the program. In their study, they had a problem with attrition of program staff, which was a problem with the program they studied rather than a problem with participatory evaluation. Nevertheless, they concluded cases of high staff attrition provided a circumstance in which it is not as favorable for participatory evaluation. 


\section{THE LOGIC MODEL AND ART PROGRAMS}

\section{Out of School Arts Programs}

There are two commonly acknowledged weaknesses in the out of school arts program evaluation literature: the lack of adequate arts program assessments and the lack of appropriate quantitative out of school program evaluations. "Educators, policy makers, and funders increasingly argue structured afterschool activities can provide youth with valuable supports for development. Studies assessing the impact of particular programs and strategies, however, are rare" (Kahne et al., 2001, p. 421).

Overall, there is a lack of evaluation of arts programs. Two things confound this situation. First, there is a lack of quantitative evaluation of the outcomes of arts programs for youth (Wright, John, Alaggia, \& Sheel, 2006). The second thing which makes it difficult to evaluate out of school arts is, in general, there is a resistance toward consideration of arts as being something which should be quantified. Rather, art programs are thought of as being a realm where students are free from the drudgery of constant and invasive standardized testing (Seidel, 1994; Soep, 2002). This problem has negatively impacted the ability to evaluate these programs and those they serve, because the evaluation of said programs is not able to show quantitatively the programs are working as intended. Possible causes of this problem are the lack of evaluation of out of school programs, and a paucity of appropriate assessments in the arts.

Holloway and LeCompte (2001) suggested art programs are different than athletic out of school pursuits in that they are not based on "interpersonal competition" (p. 389). "The arts give children a chance to acquire an additional repertory of skills for self-expression and critical thought" (p. 389). Through participant observation and interviews with attendees, they examined an out of school theater program for middle school girls. They concluded the arts helped the young women imagine new roles for themselves and new ways of dealing with violence in their lives.

Growing recognition of the importance of out of school programs signaled an increase in funding from government and foundation sources. These programs were seen as a means to enhance educational attainment, promote safety for young people, and provide additional favorable circumstances for learning art and science (Vadeboncoeur, 2006). Vadeboncoeur (2006) discussed "learning in informal contexts," which was defined as being out of school, such as art programs and museums (p. 240). Of art programs, Vadeboncoeur said:

"Youth working in programs where the medium of engagement was the visual arts, including sculpture, pottery, photography, painting 


\section{KIMBERLY A. KLEINHANS}

with both oils and watercolors, and jewelry and fashion design, were exposed to, took up, and mastered the ability to critically perceive, challenge, and ask questions of dominant social practices.” (p. 252).

Vadeboncoeur asserted young participants in out of school arts programs analyzed the circumscribed number of individual roles accessible to them from adults, and created different roles for themselves. Regarding out of school learning at museums, Vadeboncoeur remarked employees and educators at museums were positioned to be able to ask, pay attention to, and investigate youth's comprehensions, and enhance knowledge gaining encounters beyond museum walls.

According to Green and Kindseth (2011) excellent art experiences can be transformational. They found the techniques for assessing accomplishments in schools are not transferrable to out of school programs. Additionally, they surmised creating art is especially appropriate for fostering "personal growth and interpersonal connection" because of its amalgamation of dialogue and important thoughts in circumstances of personal and collective education (p. 338).

Charmaraman and Hall (2011) stated out of school art programs are able to be important actors in the prevention of youth quitting their education early. "According to the U.S. Department of Justice, after-school arts programming not only increases the academic achievement of at-risk youth but also decreases drug use and juvenile delinquency, increases self-esteem, and increases positive interactions and connections with peers and adults" (p. 18).

\section{Benefits of the Arts}

The benefits of the arts are numerous. According to McCarthy, Ondaatje, Zakaras and Brooks (2004) there are both instrumental and intrinsic benefits to society from the arts. The instrumental benefits include cognitive, attitudinal and behavioral, health, social, and economic. The intrinsic benefits of the arts include captivation, pleasure, expanded capacity for empathy, cognitive growth, creation of social bonds, and expression of communal meanings (McCarthy, Ondaatje, Zakaras \& Brooks, 2004). Hoffmann Davis (2010) found in community art centers goals such as "personal and interpersonal development, arts skill building and preprofessional training, cultural and intercultural awareness, and commitment to community service and development" are prioritized (Hoffmann Davis, 2010, p. 83). Additional benefits of the arts are detailed in Maguire et al. (2012) which include 


\section{THE LOGIC MODEL AND ART PROGRAMS}

being able to immerse oneself in imaginative individual interpretations, contemplations, and the ability to think at the macro level.

\section{Youth in Museums}

In research into the sustainability of museums, Moldavanova (2014) noted "by striving to be equitable, museums also invest in intergenerational equity. Young people who attend art classes on a scholarship, and who would not be able to do so otherwise, might eventually become parents and grandparents who will bring their children to the museum" (Moldavanova, 2014, p. 10). The museum in the present study is investing in equity by paying young adults to create programming for their peers in the museum.

In 2011, an alliance was made between four contemporary art museums to evaluate their respective youth programs. The evaluation was an investigation into five outcomes which included: personal development, arts participation, leadership, artistic and cultural literacy, and social capital. As with the case of the current study, a survey was sent out to program alumni. They found there were five compelling sectors of significance, which were: "a growth in confidence and the emergence of personal identity and self-knowledge; deep, lifelong relationships to museums and culture; a self-assured, intellectually curious pursuit of expanded career horizons and life skills; a lasting worldview grounded in art; and a commitment to community engagement and influence" (Hirzy, 2015, p. 24). The domain which is most pertinent to the current study, and is in alignment of the research of Moldavanova, is the continued connection to museums and culture.

\section{Methodology}

\section{Procedures}

The evaluation design was a participatory logic model. Participatory methods gleaned from the literature review were utilized along with the best practices for creating a logic model. The subject of the evaluation was an out of school arts program at an art museum. This was a summative evaluation, as it examined the out of school arts program to provide "information to serve decisions or assist in making judgements about a program's overall worth or merit in relation to important criteria" (Fitzpatrick, Sanders \& Worthen, 2012, pp. 21). The stakeholders for this evaluation were the participants, alumni, program staff, family members of participants, and the museum's executive director. The evaluator was 


\section{KIMBERLY A. KLEINHANS}

chosen because this individual was employed by the museum, and performed internal evaluations as part of funding requirements.

The logic model was constructed by using a semi-structured interview protocol adapted from Gugiu and Rodríguez -Campos (2007). The stakeholders were interviewed using a semi-structured interview protocol. The alumni were contacted to participate in the evaluation as survey respondents. A survey was created to test the underlying assumptions of the logic model, a step in the logic model process which is not always done (Kaplan \& Garrett, 2004). There was a pre-existing logic model which was part of the program documents available for review. This logic model did not exhibit best practices for logic models, because it is overly wordy and has no research backing up the assertions as to the program outcomes. As discussed in the Literature Review, Renger and Titcomb (2002) warned against trying to fit too much information into a logic model, because the more boxes there are, the more likely the "underlying rationale" (p. 495) becomes occluded. The original logic model for the program can be seen as Figure 2 below, with identifying information redacted.

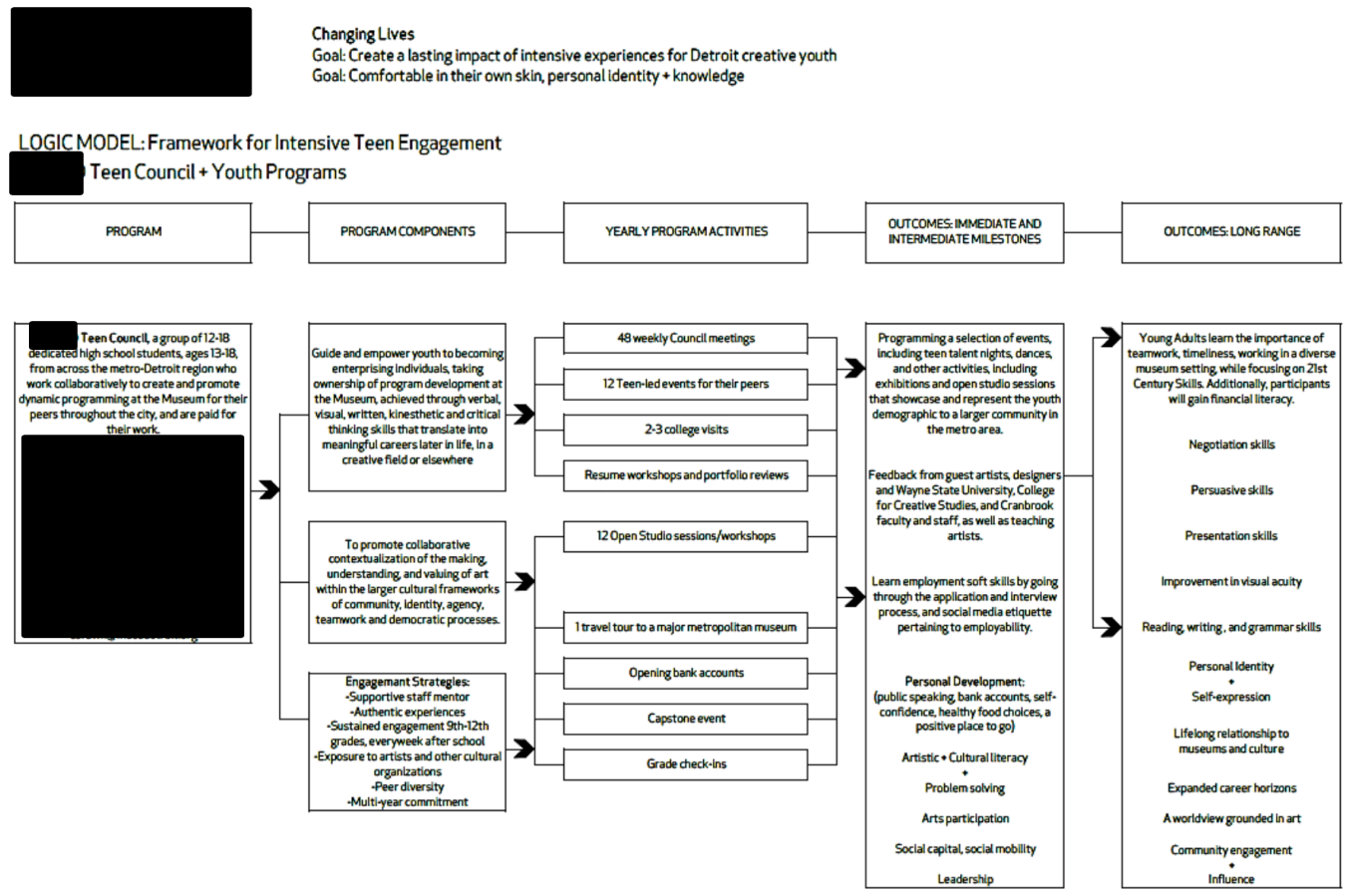

Figure 2. Original Logic Model 


\section{THE LOGIC MODEL AND ART PROGRAMS}

\section{Program Documents (2017)}

Survey instruments were completed by alumni of the program, after being piloted by three alumni. The survey utilized retrospective pretest-posttest design to determine any effects of the out of school arts program on the participants. Retrospective pretest-posttest is a variation on Campbell and Stanley (1963) "OneGroup Pretest-Posttest Design" (p. 7). Campbell and Stanley (1963) listed the onegroup pretest-posttest design as type of design as one which is "worth doing when nothing better can be done" (p. 7). Howard, Schmeck, and Bray (1979) posited "retrospective pretests" (p. 129) are a remedy for some internal invalidity concerns of the pretest-posttest design when there is self-reporting of changes. According to Pratt, McGuigan, and Katzev (2000), "actual changes in knowledge and behaviors may be masked if the participants overestimate their knowledge and skills on the pretest," and a retrospective pretest is a suggested as a remedy for this (p. 342).

The target population was former participants in the out of school arts program. According to program documents, qualifying youth for the program were between the ages of 13-18 from throughout a major metropolitan area. The youth applied to take part in the program and went through an interview process, from which youth were selected to join the program. While some youth showed portfolios of their artwork as part of the interview process, it was not required. The youth met one day per week and planned programming for their peers. Art activities included workshops in a variety of media, drawing fundraisers, art exhibitions, and portfolio reviews. Teen nights at the museum included lock-ins (teens stayed overnight at the museum), game nights, Halloween-themed events, and open mic nights (talent shows). The youth were paid a monthly stipend for their work at the museum. The program has been in existence since the 2013-2014 school year. There were a total of 35 former youth participants for whom there was contact information. As was found in Quintanilla and Packard (2002), there was little follow up with alumni.

The sampling for this evaluation was up to 35 individuals including current participants and alumni over the age of 18. As the total number of former participants is 35 , all of the individuals were contacted to participate in the survey. Using a sample size calculator at http://www.raosoft.com/samplesize.html, if 33 participants responded, for a population this size, there would be a $95 \%$ confidence level. A sample size calculator was used to determine the confidence level depending on the actual number of responses. Respondents were contacted by email to become informed about the evaluation. Follow up emails included consent forms. Data collection was done through an online survey form through Qualtrics. Links 


\section{KIMBERLY A. KLEINHANS}

to the survey were sent via email to the respondents. Data collected was organized by using Microsoft Excel.

Reliability was calculated using Cronbach's alpha, a measure of internal consistency. The item-deletion method was used to examine candidates for exclusion. The reliability estimates for subscales created via exploratory factor analysis (EFA, see below) were obtained via the Spearman-Brown prophecy formula.

Internal structure validity was assessed through EFA, using SPSS version 25. Principal components extraction was used via setting the Kaiser Eigenvalue criterion, as well as scree plots. The varimax rotation was used with the coefficients sorted by size. The EFA was conducted in two ways:

1. Retention of all items with a single pass.

2. An iterative approach where coefficients will be sorted according to size, values less than $|.4|$ suppressed, and items which load on more than one factor or fail to load were deleted. This process was repeated until the factor solution was resolved.

\section{Data Analysis}

As the survey instrument consisted of Likert-scale type items, the scale of measurement for these items was ordinal. Some items on the survey were ratio such as number of years as a participant in the program, and number of other out of school programs attended.

The statistical test which was used was the Wilcoxon signed-rank test. There were numerous reasons to the use of the Wilcoxon signed-rank procedure rather than the $t$-test under these particular circumstances, where a Likert scale will be used with matched pairs. Additionally, there was a small sample size and it was unlikely for there to be normally shaped data. A Likert scale produces ordinal data, and thus the permissible statistical procedures are those utilizing the median rather than the mean (Stevens, 1946). Blair and Higgins (1985) asserted "when the normality assumption is relaxed the [Wilcoxson signed-rank] test can attain truly large (in theory, infinitely large) advantages over the $t$ test" (p. 121). According to Neave and Worthington (1988), the Wilcoxson signed-rank test is appropriate for matched pairs. Sawilowsky (1990) was a proponent of rank tests, saying "no assumption is made about the shape of the population from which samples are drawn, unlike the normality assumption of parametric tests" (p. 94), and "the data need to be measured only on an ordinal scale" (p. 94). Rosner, Glynn and Lee 


\section{THE LOGIC MODEL AND ART PROGRAMS}

(2006) said "The Wilcoxon signed-rank test is a frequently used nonparametric test for paired data (e.g., consisting of pre- and posttreatment measurements)" (p. 185). Meek, Ozgur and Dunning (2007) stated the Wilcoxon signed-rank test "should be used if the assumptions of normality and interval measurement are questionable, particularly in small sample situations" (p. 93), and the "Wilcoxon signed-rank procedure is a test of the population median" (p. 93). Further, Meek, Ozgur and Dunning (2007) said the data should be symmetrical, but the Wilcoxon signed-rank test also works for data which are asymmetrical. Nominal alpha was set at 0.05

\section{Results}

\section{Survey}

A survey was constructed which contained Likert scale, closed-ended items, and one open ended item. This survey was piloted with three individuals, one current Teen Council member who was over the age of 18, and two former Teen Council members, also over the age of 18 . The survey was distributed via email. The pilot subjects gave feedback on the survey which led to rewording of one Likert scale item by breaking one item into two different items for clarity, and adding an additional open-ended item. The original survey instrument had 20 items, and the revised survey instrument had 23.

Once the survey was finalized, it was sent via email to 35 Teen Council alumni. Several subjects had invalid email addresses, in which case their parents were contacted to obtain up-to-date contact information. The survey was open for two months, and subjects were contacted to remind them about the survey two weeks after the initial email was sent. There were 16 total responses. One respondent declined to participate, and four respondents agreed to participate but did not complete any other items on the survey, leaving 11 total respondents for which there was a significant amount of completeness to the responses to be included in the analysis.

Analysis of the dimensionality of the 14 Likert scale items was performed using Factor Analysis. There were a total of 11 cases. The case processing summary indicated that, of the 11, there were 10 valid cases (See Table 1). Without any excluding of items, the Cronbach's Alpha was .618 (See Table 2). The original scree plot appeared to indicate that there were between 5 and 6 factors.

Factor Analysis was performed using principal components, and a varimax rotation. The results were sorted by factor, with suppression of any scores which

were less than $|.4|$. There was listwise deletion for missing scores. The procedure 


\section{KIMBERLY A. KLEINHANS}

was completed two times, with removal of factors after each. The first time, items Q2R, Q3R, Q5R, Q3O, Q2O, and Q4O were removed because of multiple loadings. The second time, Q1R was deleted. Finally, 7 items were included, loading on three factors with four iterations (see Table 4). The explained variance for these 3 factors was a cumulative $81 \%$ (see Table 5). After items were excluded through factor analysis, Cronbach's Alpha was again computed, this time with a 0.344 reliability (see Table 3). The Spearman Brown prediction was then computed using an Excel spreadsheet from (http://www.larrynelsonstuff.com/HTMLHelp/Lrtp59HTML/ spearman_brown.htm). This spreadsheet features four columns: original Alpha value, original number of items, and new number of items, with the fourth column being the new Alpha calculated by an Excel formula. The Spearman Brown prediction results were if the instrument was increased to 30 items, which load on the three factors, the new Alpha would be 0.974, which rounds up to 1.0.

Table 1. Case Processing Summary

\begin{tabular}{lrr} 
Cases & N & \% \\
\hline Valid & 10 & 90.9 \\
Excluded & 1 & 9.1 \\
Total & 11 & 100.0 \\
\hline
\end{tabular}

Note: a. Listwise deletion based on all variables in the procedure.

Table 2. Reliability Statistics Before Item Removal

Cronbach's Alpha

$\mathbf{N}$ of Items 0.618

14

Table 3. Reliability Statistics After Item Removal

Cronbach's Alpha

0.344
$\mathbf{N}$ of Items

7 


\section{THE LOGIC MODEL AND ART PROGRAMS}

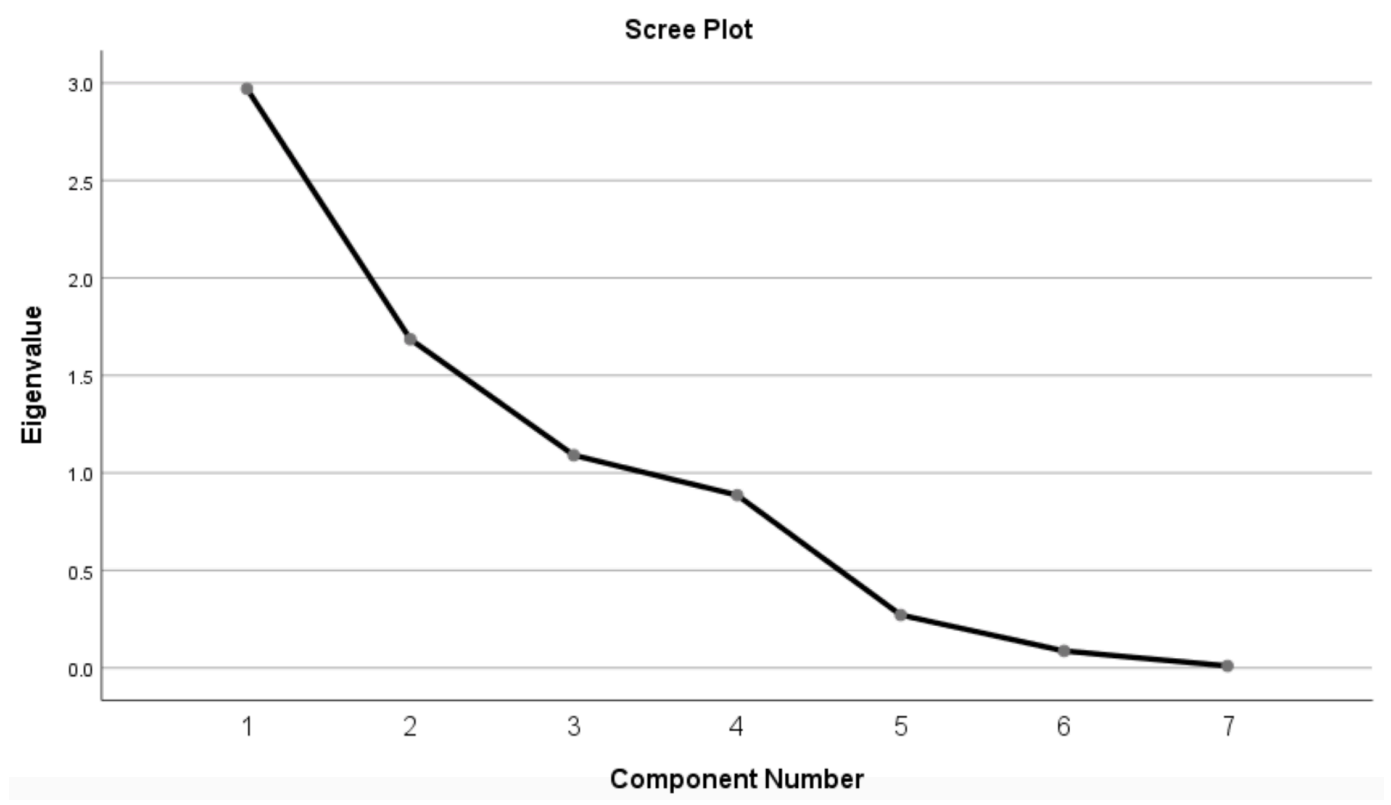

Figure 3. Scree plot for factor analysis

A Scree Plot was generated (see Figure 3). As it goes down it indicates factors, but when it is going more to the right (horizontal) than down (vertical) there are no more factors. The Scree Plot appeared to indicate there are three factors, as the line becomes more horizontal than vertical between three and four.

Table 4. Rotated Component Matrix ${ }^{a}$ After Item Deletion

\begin{tabular}{lccc} 
& \multicolumn{3}{c}{ Component } \\
\cline { 2 - 4 } & $\mathbf{1}$ & $\mathbf{2}$ & $\mathbf{3}$ \\
\hline Q70 & 0.963 & & \\
Q7R & 0.960 & & \\
Q10 & 0.951 & 0.927 & \\
Q60 & & 0.862 & 0.846 \\
Q6R & & & -0.642 \\
Q4R & & & \\
Q50 & & & \\
\hline
\end{tabular}

Note: Extraction Method: Principal Component Analysis; Rotation Method: Varimax with Kaiser Normalization; a. Rotation converged in 4 iterations. 


\section{KIMBERLY A. KLEINHANS}

Table 5. Total Variance Explained

\begin{tabular}{cccc} 
& \multicolumn{3}{c}{ Rotation Sums of Squared Loadings } \\
\cline { 2 - 4 } Component & Total & \% of Variance & Cumulative \% \\
\hline 1 & 2.837 & 40.530 & 40.530 \\
2 & 1.737 & 24.812 & 65.342 \\
3 & 1.173 & 16.750 & 82.092 \\
\hline
\end{tabular}

Note: Extraction Method: Principal Component Analysis;

A Wilcoxon test was conducted to evaluate change from before to after Teen Council participation on seven different topics: plans for career, plans for college, appreciation for art museums, the ability to question the status quo, leadership skills, knowledge of how to plan events, and the importance of school attendance. The results indicated significant differences, with a critical value of $p<0.05$, for leadership skills (.005) and knowledge of how to plan events (.002). The results indicated there were not significant differences for appreciation for art museums (.059), plans for college (.705), plans for career (.705), the ability to question the status quo (.129), and placing importance on school attendance (.317). See Table 6.

Table 6. Wilcoxon Signed Ranks Test

\begin{tabular}{rrrrrrrr} 
& Q10 - Q1R & Q20 - Q2R & Q30 - Q3R & Q40 - Q4R & Q50 - Q5R & Q60 - Q6R & Q70 - Q7R \\
\hline$Z^{\text {a }}$ & -1.633 & -0.378 & -1.890 & -1.518 & -2.810 & -3.025 & -1.000 \\
Asymp. Sig. (2-tailed) & 0.102 & 0.705 & 0.059 & 0.129 & 0.005 & 0.002 & 0.317 \\
\hline
\end{tabular}

Note: a. Q7O-Q7R based on positive ranks; all other $Z$ based on negative ranks.

The confidence level of the study was calculated using an online sample size calculator found at: http://www.raosoft.com/samplesize.html. For a total population of 35, with 11 survey responses as the sample, the confidence level of the study is $30 \%$. 
THE LOGIC MODEL AND ART PROGRAMS

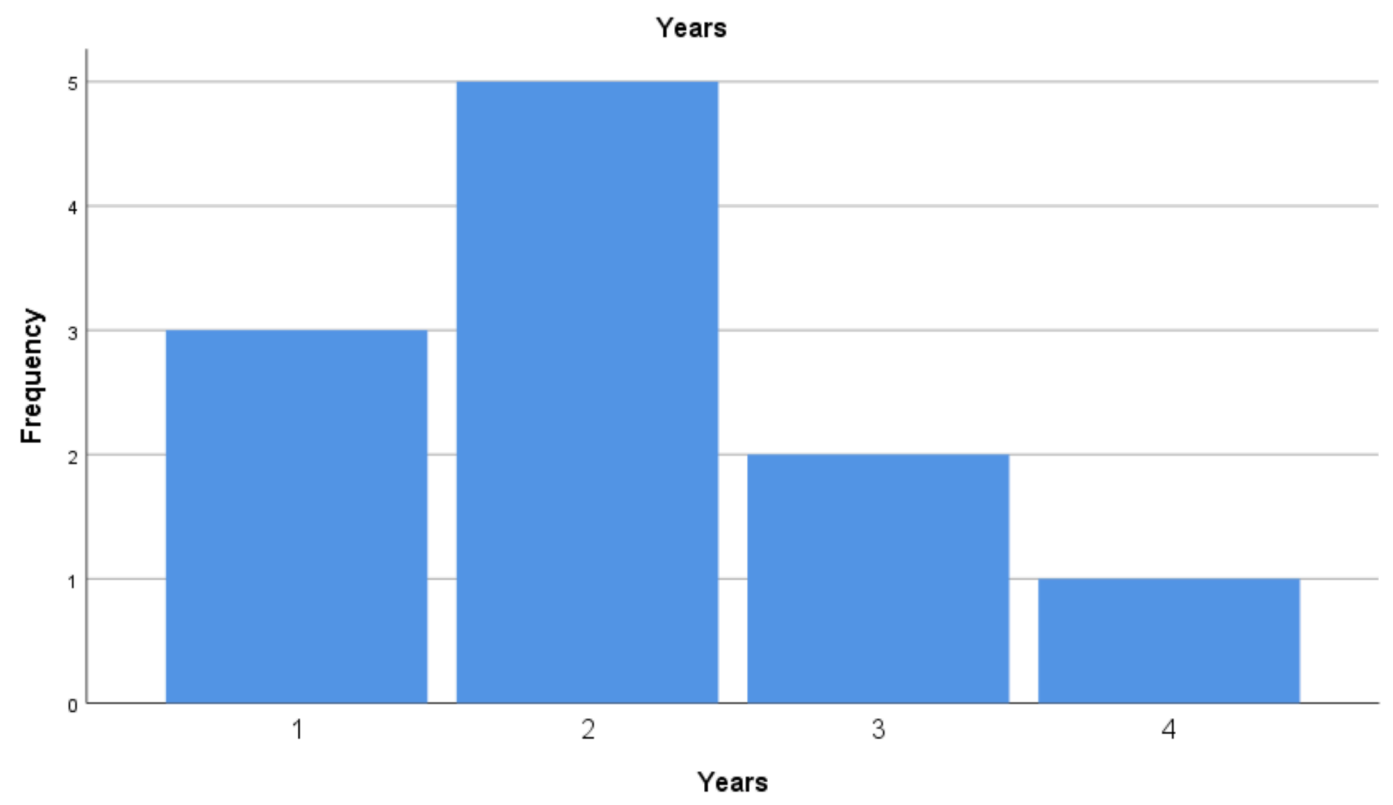

Figure 4. Number of Years of Participation in Program

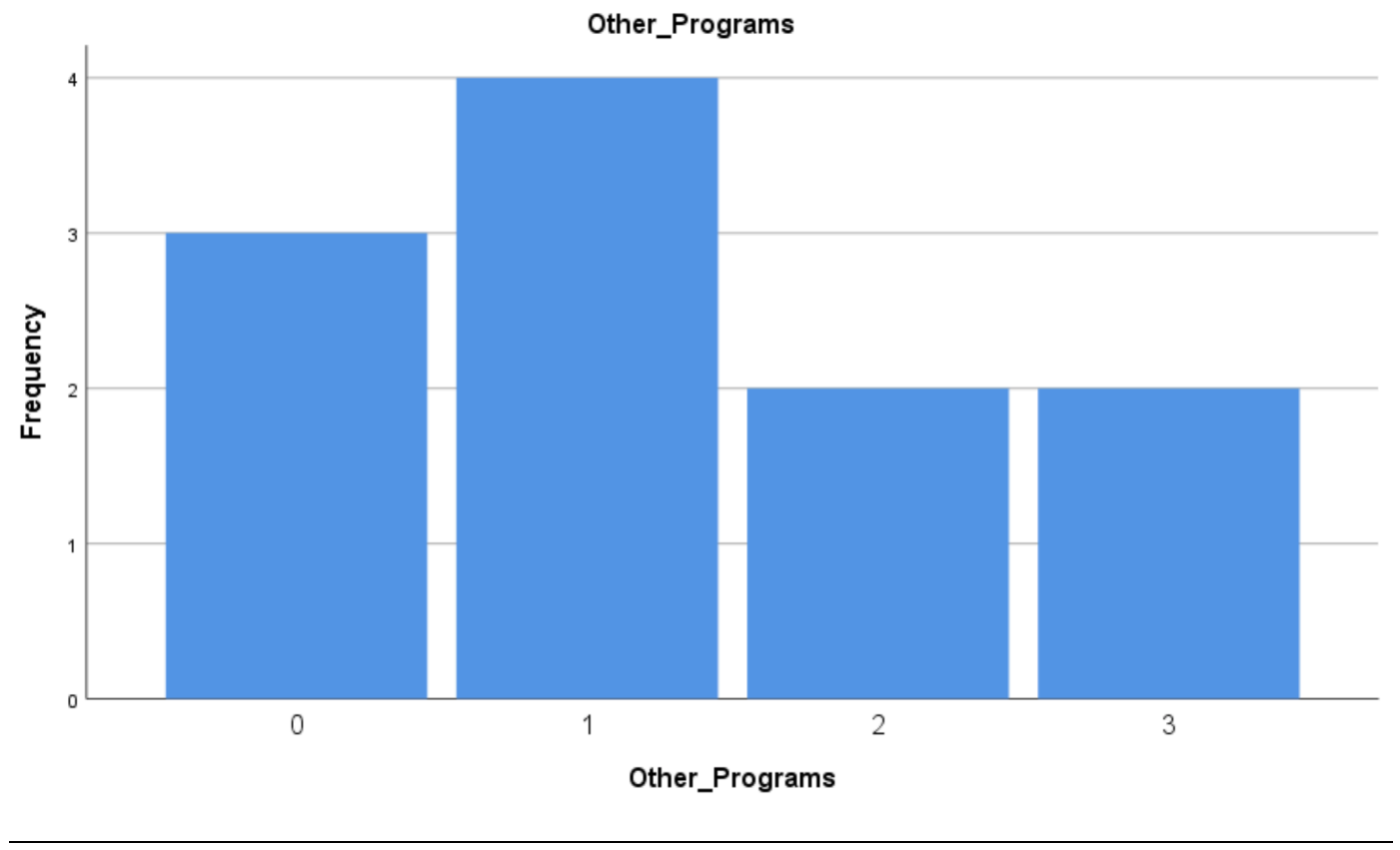

Figure 5. Number of Other Out of School Programs Attended 


\section{KIMBERLY A. KLEINHANS}

One respondent indicated that they participated in the Teen Council for four years, two for three years, five for two years and three for one year (See Figure 4). Two respondents participated in three or more other out of school programs, two participated in two, four participated in one, and three did not participate in any other out of school programs (see Figure 5).

All but one respondent were attending college, and $100 \%$ of the respondents were working. $72 \%$ of the respondents indicated their experience on the Teen Council was their first job. $81 \%$ of the respondents said they have visited an art museum besides the one in which they were previously employed since they ended their tenure on the Teen Council.

The open-ended responses indicated the alumni felt they received overall a good experience, and they had increased job prospects because of their work on the Teen Council. Additionally, it was mentioned the experience on the Teen Council led to increased confidence. One respondent had some negative feedback for the program, suggesting that a turnover in program leadership led to increased chaos in the program.

\section{Interviews}

A total of three interviews were given, two with program personnel and one with a family member of a Teen Council alumnus. Two additional potential interviewees, former program managers, were contacted to participate in the study, but declined to participate. The interviews followed a semi-structured interview protocol based on Gugiu and Rodríguez -Campos (2007). Besides the survey, the interviews and subsequent follow-up were the main participatory components of the study. Themes which were apparent in the interviews were: the program provides opportunities to experience art instruction, youth learn how to plan and organize events, the program causes increased youth participation at the museum, selfconfidence is increased because of the program, opportunities for engaging in the community are increased for the youth in the program, youth gain knowledge that their voices are important, there is an increased intergenerational relationship to museums and culture, and youth learn cooperation and promptness. All three interviewees mentioned a lack of adequate funding is a hindrance to the implementation of the program.

\section{Logic Model Construction}

A new logic model for the program was constructed by utilizing participatory feedback from the survey and interviews. Feedback from the interviews and 


\section{THE LOGIC MODEL AND ART PROGRAMS}

positive results from the survey were used to create outcomes. The yearly program activities section of the logic model only needed slight modifications from the original logic model to accurately reflect the current program activities. Once the revised logic model was constructed, it was reviewed with two of the three interview subjects for additional edits. The third interview subject was not available for further consultation due to their moving out of the country. See Figure 6 for the new logic model.

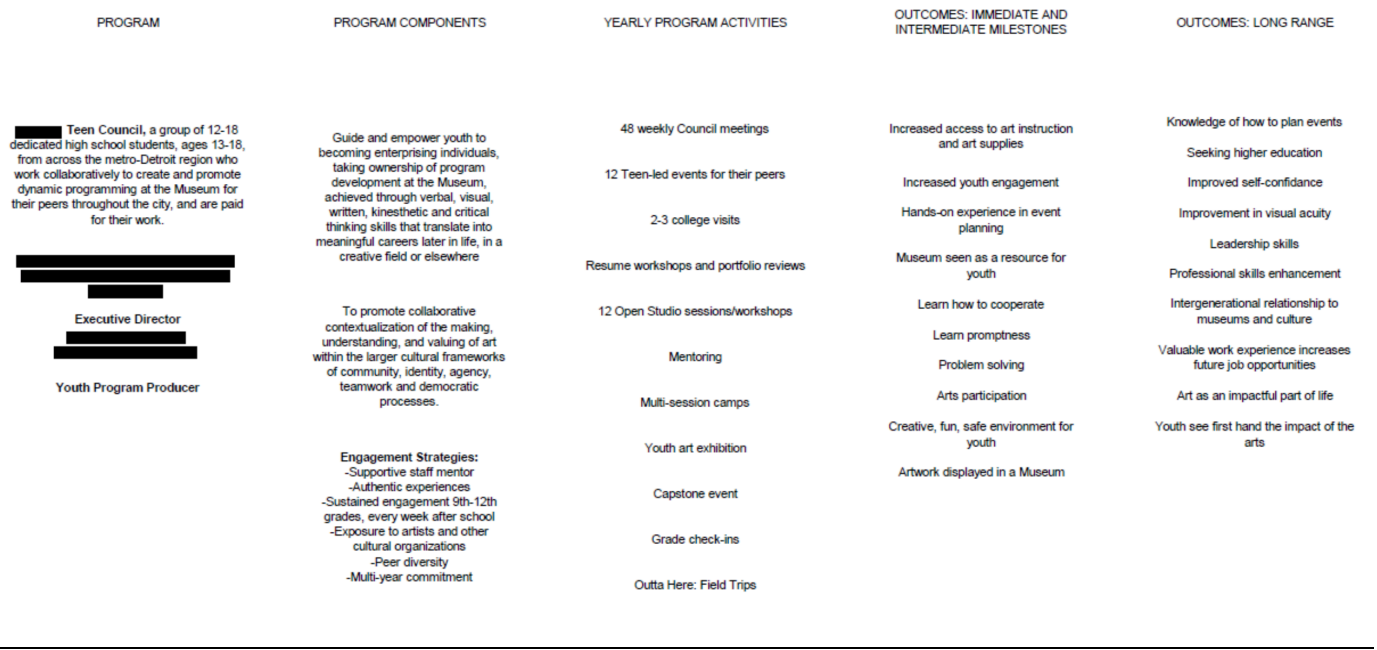

Figure 6. New Logic Model

The new logic model displays updates to the program activities, removing activities from the original logic model which were not actually part of the program such as opening bank accounts and travel tours to major metropolitan museums, and adding activities which were not on the original logic model such as teen art exhibition and field trips.

Table 7 shows the details of the participatory sources for the immediate and intermediate outcomes on the new logic model. The three sources are the stakeholder interview, the follow-up consultation with the stakeholders, and the alumni survey. The outcomes from the alumni survey include items that were found to be significant in the statistical analysis as well as items that were evident from the answers to the open-ended responses. Likewise, Table 8 details the long-range outcomes depicted in the new logic model, with sources identified. 


\section{KIMBERLY A. KLEINHANS}

Table 7. Participatory Sources of Logic Model Immediate and Intermediate Outcomes

\begin{tabular}{ll} 
Outcomes: Immediate and Intermediate Milestones & Participatory Source \\
\hline Increased access to art instruction and art supplies & Stakeholder Interview \\
Increased youth engagement & Stakeholder Interview \\
Hands-on experience in event planning & Stakeholder Interview, Alumni Survey \\
Museum seen as a resource for youth & Stakeholder Interview \\
Learn how to cooperate & Stakeholder Interview \\
Learn promptness & Stakeholder Interview \\
Problem solving & Stakeholder Interview \\
Arts participation & Stakeholder Interview \\
Creative, fun, safe environment for youth & Stakeholder Interview \\
Artwork displayed in a Museum & Stakeholder Follow-up Consultation \\
\hline
\end{tabular}

Table 8. Participatory Sources of Logic Model Long Range Outcomes

Outcomes: Long Range

Knowledge of how to plan events

Seeking higher education

Improved self-confidence

Improvement in visual acuity

Leadership skills

Professional skills enhancement

Intergenerational relationship to museums and culture

Valuable work experience increases future job opportunities

Art as an impactful part of life

Youth see firsthand the impact of the arts
Participatory Source

Stakeholder Interview, Alumni Survey

Stakeholder Interview

Stakeholder Interview, Alumni Survey

Stakeholder Interview

Alumni Survey

Stakeholder Interview

Stakeholder Interview

Alumni Survey

Stakeholder Follow-up Consultation

Stakeholder Follow-up Consultation

\section{Conclusion}

Although it is rarely possible to construct a logic model without utilizing participatory elements, this essential association is not recognized in the literature. In the case of this study, the original logic model was constructed by institutional staff only without including any other stakeholders. The new logic model, which was constructed with feedback from many stakeholders, more accurately depicted the short-term and long-term outcomes of the program. Thus, it is evident that increasing participatory elements to a logic model evaluation design leads to a more accurate model of the program and its outcomes. Likewise, using a logic model improves the participatory evaluation process by introducing a structured element to the proceedings. 


\section{THE LOGIC MODEL AND ART PROGRAMS}

Another way to look at the combined methodology, rather than focusing on adding participatory elements to a logic model evaluation, is to view the methodology as adding a logic model to a participatory evaluation. Either way, the use of nonparametric methods to analyze the data is ideal, as nonparametric methods are designed for use for qualitative data such as the Likert scale that are measured in the ordinal scale.

The survey indicated gains in leadership skills and the ability to plan events in participants. One survey item which did not indicate an effect from the program was plans for college, which may be an indication that participants had plans for college prior to becoming a participant in the program. Likewise, plans for a career were not a valid outcome for the alumni of the program, which may indicate participants have career plans before entering the program. While plans for a career were not statistically significant in the survey, in the open-ended items there were responses which indicated some career benefits stemming from the program. One respondent specifically stated their current position was the result of their participation in the program. They said: "Working at [the museum] instilled in me a love for non-profit work, specifically in relation to the arts, youth and community building. This summer I'll be working as a Family/Event Coordinator for [another non-profit] and that's because of all the experience I got at [the museum]!" This kind of testimonial can lend itself to the conclusion the program indeed provides valuable work experience which increases future job opportunities, even though the specific results from the statistical analysis does not support this conclusion. In participatory evaluation, stakeholder feedback is an important source of evidence to show if and how the program is working, thus the logic model reflects this outcome.

The survey included several questions designed to elicit information regarding possible covariates which include number of years participating in the program and the number of other out of school programs in which the respondents also participated. Only three out of the eleven respondents participated in zero other out of school programs. With 73 percent of the respondents participating in at least one other additional out of school program, there is a possibility that the documented outcomes could have been influenced by these other programs. In Kahne et al. (2001) it was noted it is difficult to ascribe positive youth development to any specific program because youth often take part in multiple out of school activities. Additionally, it is difficult to establish provenience of youth development benefits because participants are self-selected causing selection bias. Additionally, the respondents were asked about how many years they participated in the Teen 


\section{KIMBERLY A. KLEINHANS}

Council program, with eight out of the eleven respondents participating in the program for multiple years.

The problem of staff attrition in participatory evaluation, as noted by Jacob, Ouvrard, and Belanger (2011), was a reality of this study. One research participant who was a program manager and the main mentor of the youth moved out of the country and was unavailable for additional consultation after the first interview.

\section{Recommendations}

Overall, the Teen Council program at the museum has a positive effect on participants, with the survey results indicating youth participants make gains in leadership skills and the ability to plan events. The organization should continue to implement the program. Revising the program's logic model to incorporate participatory feedback from the alumni survey and stakeholder interviews led to a more accurate representation of the programmatic outcomes.

Unfortunately, not all of the feedback gleaned from stakeholders was positive, with specific reference to changes in program leadership. A recommendation for future program implementation is to make sure the program leader is a good facilitator of group discussions. Specific feedback mentioned there was no incentive for program participants to be prompt and have a good attendance record, which is something which had been changed already in the program since the respondent was a participant. Youth in the program when it was evaluated received a reduction in pay for absences and habitual tardiness, and this policy should continue to assure fairness for all involved. Turnover in program leadership is not easily quelled, but the organization should put forth efforts to maintain steady leadership in the role of facilitator and main mentor.

In addition to the recommendations for the organization, recommendations for future research were considered. If the study were to be repeated with appropriate resources, a different design could be utilized wherein three evaluations were performed: one logic model only, one participatory only, and a third which would be a combination of the logic model and participatory evaluation. The three evaluations could then be compared to see which was the most effective. A future study could include additional demographics of the participants such as age, gender or ethnicity. Additionally, a future study could include more interviews with participants and alumni. Finally, as this study only looked at the instrumental benefits of the out of school art program, a future study could take a closer look at the intrinsic benefits. 


\section{THE LOGIC MODEL AND ART PROGRAMS}

\section{Acknowledgments}

This paper is developed in part from the author's unpublished dissertation sharing the same title (Kleinhans, 2018), and elements throughout are derived from that work.

\section{References}

Blair, R. C., \& Higgins, J. J. (1985). Comparison of the power of the paired samples $t$ test to that of Wilcoxon's signed-ranks test under various population shapes. Psychological Bulletin, 97(1), 119-128. https://doi.org/10.1037/0033-2909.97.1.119

Boody, R. M. (2009). A rationale for participant evaluation. Educational Research Quarterly, 32(3), 47-59.

Brisolara, S. (1998). The history of participatory evaluation and current debates in the field. New Directions for Evaluation, 1998(80), 25-41.

https://doi.org/10.1002/ev.1115

Burke, B. (1998). Evaluating for a change: Reflections on participatory methodology. New Directions for Evaluation, 1998(80), 43-56. https://doi.org/10.1002/ev.1116

Campbell, D. T., \& Stanley, J. C. (1963). Experimental and quasi-experimental designs for research. Boston, MA: Houghton Mifflin Company.

Charmaraman, L., \& Hall, G. (2011). School dropout prevention: What arts-based community and out-of-school-time programs can contribute. New Directions for Youth Development, 2011(S1), 9-27. https://doi.org/10.1002/yd.416

Cooksy, L. J., Gill, P., \& Kelly, P. A. (2001). The program logic model as an integrative framework for a multimethod evaluation. Evaluation and Program Planning, 24(2), 119-128. https://doi.org/10.1016/s0149-7189(01)00003-9

Cousins, J. B., \& Whitmore, E. (1998). Framing participatory evaluation. New Directions for Evaluation, 1998(80), 5-23. https://doi.org/10.1002/ev.1114

Epstein, D., \& Klerman, J. A. (2013). When is a program ready for rigorous impact evaluation? The role of the falsifiable logic model. Evaluation Review, 36(5), 375-401. https://doi.org/10.1177/0193841X12474275

Fiero, R. S. (2016). Enhancing facilitation skills: Dancing with dynamic tensions. New Directions for Evaluation, 2016(149), 31-42. https://doi.org/10.1002/ev.20177 


\section{KIMBERLY A. KLEINHANS}

Fitzpatrick, J. L., Saunders, J. R., \& Worthen, B. R. (2012). Program evaluation: Alternative approaches and practical guidelines (4th ed.). Upper Saddle River, NJ: Pearson.

Flores, K. S. (2008). Youth participatory evaluation: Strategies for engaging young people. San Francisco, CA: Jossey-Bass.

Green, J., \& Kindseth, A. (2011). Art all day: Distinction and interrelation of school-based and out-of-school arts learning. Studies in Art Education, 52(4), 337-341. https://doi.org/10.1080/00393541.2011.11518845

Greene, K. M., Lee, B., Constance, N., \& Hynes, K. (2012). Examining youth and program predictors of engagement in out-of-school time programs. Journal of Youth and Adolescence, 42(10), 1557-1572. https://doi.org/10.1007/s10964-012-9814-3

Gugiu, P. C., \& Rodríguez-Campos, L. (2007). Semi-structured interview protocol for constructing logic models. Evaluation and Program Planning, 30(4), 339-350. https://doi.org/10.1016/j.evalprogplan.2007.08.004

Hirzy, E. (Ed.). (2015). Room to rise: The lasting impact of intensive teen programs in art museums. New York, NY: Whitney Museum of American Art.

Hoffmann Davis, J. (2010). Learning from examples of civic responsibility: What community-based art centers teach us about arts education. Journal of Aesthetic Education, 44(3), 82-95. https://doi.org/10.1353/jae.2010.0001

Holloway, D. L., \& LeCompte, M. D. (2001, August). Becoming somebody! How arts Programs support positive identity for middle school girls. Education and Urban Society, 33(4), 388-408. https://doi.org/10.1177/0013124501334004

Howard, G. S., Schmeck, R. R., \& Bray, J. H. (1979). Internal invalidity in studies employing self-report instruments: A suggested remedy. Journal of Educational Measurement, 16(2), 129-135. https://doi.org/10.1111/j.1745-3984.1979.tb00094.x

Isaacs, B., Perlman, N., \& Pleydon, A. (2004). Limitations in the scope of logic models: Social climate and context [Abstract]. Journal of Intellectual Disability Research, 48(4-5), 515. https://doi.org/10.1111/j.1365-2788.2004.00615.x

Jacob, S., Ouvrard, L., \& Belanger, J. (2011). Participatory evaluation and process use within a social aid organization for at-risk families and youth. Evaluation and Program Planning, 34(2), 113-123. https://doi.org/10.1016/j.evalprogplan.2010.08.002

Jardine, C. G., \& James, A. (2012). Youth researching youth: Benefits, limitations and ethical considerations within a participatory research process. International Journal of Circumpolar Health, 71(1), 18415. https://doi.org/10.3402/ijch.v71i0.18415 


\section{THE LOGIC MODEL AND ART PROGRAMS}

Julian, D. A., Jones, A., \& Deyo, D. (1995). Open systems evaluation and the logic model: Program planning and evaluation tools. Evaluation and Program Planning, 18(4), 333-341. https://doi.org/10.1016/0149-7189(95)00034-8

Kahne, J., Nagaoka, J., Brown, A., O'Brien, J., Quinn, T., \& Thiede, K. (2001, June). Assessing after-school programs as contexts for youth development. Youth \& Society, 32(4), 421-446. https://doi.org/10.1177/0044118x01032004002

Kaplan, S. A., \& Garrett, K. E. (2005). The use of logic models by communitybased initiatives. Evaluation and Program Planning, 28(2), 167-172.

https://doi.org/10.1016/j.evalprogplan.2004.09.002

King, J. A. (1998). Making sense of participatory evaluation practice. New Directions for Evaluation, 1998(80), 57-67. https://oi.org/10.1002/ev.1117

Kleinhans, K. (2018). The Logic Model, Participatory Evaluation And Out Of School Art Programs (Paper 2109) [Doctoral Dissertation, Wayne State University]. Digital Commons at Wayne State University. https://digitalcommons.wayne.edu/oa_dissertations/2109/

Little, P. M. D., Wimer, C., \& Weiss, H. B. (2008). After school programs in the 21st century: Their potential and what it takes to achieve it. Issues and Opportunities in Out-Of-School Time Evaluation [Harvard Family Research Project], 10, 1-12. Retrieved from https://archive.globalfrp.org/evaluation/publications-resources/after-schoolprograms-in-the-21st-century-their-potential-and-what-it-takes-to-achieve-it

Maguire, C., Donovan, C., Mishook, J., de Gaillande, G., \& Garcia, I. (2012). Choosing a life one has reason to value: the role of the arts in fostering capability development in four small urban high schools. Cambridge Journal of Education, 42(3), 367-390. https://doi.org/10.1080/0305764x.2012.706258

McCarthy, K. F., Ondaatje, E. H., Zakaras, L., \& Brooks, A. (2004). Gifts of the Muse: Reframing the Debate About the Benefits of the Arts. Santa Monica, CA: RAND Corporation. https://doi.org/10.7249/mg218

McLaughlin, J. A., \& Jordan, G. B. (1999). Logic models: a tool for telling your program's performance story. Evaluation and Program Planning, 22(1), 65-72. https://doi.org/10.1016/s0149-7189(98)00042-1

Meek, G. E., Ozgur, C., \& Dunning, K. (2007). Comparison of the $t$ vs. Wilcoxon signed-rank test for Likert scale data and small samples. Journal of Modern Applied Statistical Methods, 6(1), 91-106. https://doi.org/10.22237/jmasm/1177992540

Moldavanova, A. (2014). Two narratives of intergenerational sustainability: A framework for sustainable thinking. The American Review of Public Administration, 46(5), 526-545. https://doi.org/10.1177/0275074014565390 


\section{KIMBERLY A. KLEINHANS}

Neave, H. R., \& Worthington, P. L. (1988). Distribution-free tests. London, UK: Unwin Hyman.

O'Donnell, J., \& Kirkner, S. L. (2014). Effects of an out-of-school program on urban high school youth's academic performance. Journal of Community Psychology, 42(2), 176-190. https://doi.org/10.1002/jcop.21603

Powers, J. L., \& Tiffany, J. S. (2006). Engaging youth in participatory research and evaluation. Journal of Public Health Management Practice, 12, S79-S87. https://doi.org/10.1097/00124784-200611001-00015

Pratt, C. C., McGuigan, W. M., \& Katzev, A. R. (2000). Measuring program outcomes: Using retrospective pretest methodology. American Journal of Evaluation, 21(3), 341-349. https://doi.org/10.1177/109821400002100305

Quintanilla, G., \& Packard, T. (2002). A participatory evaluation of an inner-city science enrichment program. Evaluation and Program Planning, 25(1), 15-22. https://doi.org/10.1016/s0149-7189(01)00045-3

Renger, R., \& Titcomb, A. (2002). A three-step approach to teaching logic models. American Journal of Evaluation, 23(4), 493-503. https://doi.org/10.1177/109821400202300409

Rosner, B., Glynn, R. J., \& Lee, M. T. (2006). The Wilcoxon signed rank test for paired comparisons of clustered data. Biometrics, 62(1), 185-192.

https://doi.org/10.1111/j.1541-0420.2005.00389.x

Sawilowsky, S. S. (1990). Nonparametric tests of interaction in experimental design. Review of Educational Research, 60(1), 91-126. https://doi.org/10.3102/00346543060001091

Seidel, K. (1994, April). Developing successful arts program evaluation. National Association of Secondary School Principals Bulletin, 78(561), 7-19.

https://doi.org/10.1177/019263659407856103

Soep, S. (2002). Arts in the city. Kappa Delta Pi Record, 39(1), 12-16. https://doi.org/10.1080/0028958.2002.10516375

Stevens, S. S. (1946). On the theory of scales of measurement. Science, 103(2684), 677-680. https://doi.org/10.1126/science.103.2684.677

United Way of America. (1998). Measuring program outcomes: A practical approach. N.p.: Author.

Turnbull, B. (1999). The mediating effect of participation efficacy on evaluation use. Evaluation and Program Planning, 22(2), 131-140. https://doi.org/10.1016/s01497189(99)00012-9 


\section{THE LOGIC MODEL AND ART PROGRAMS}

Vadeboncoeur, J. A. (2006). Engaging young people: Learning in informal contexts. Review of Research in Education, 30(1), 239-278.

https://doi.org/10.3102/0091732x030001239

W.K. Kellogg Foundation. (2004). Using logic models to bring together planning, evaluation, and action: Logic model development guide. Battle Creek, MI: W.K. Kellogg Foundation.

https:/www.bttop.org/sites/default/files/public/W.K.\%20Kellogg\%20LogicModel.pdf

W. K. Kellogg Foundation. (2017). The Step-by-Step Guide to Evaluation: How to Become Savvy Evaluation Consumers. Battle Creek, MI: Author.

Whitmore, E. (1998). Final commentary. New Directions for Evaluation, 1998(80), 95-99. https://doi.org/10.1002/ev.1120

Wright, R., John, L., Alaggia, R., \& Sheel, J. (2006, December). Community-based arts program for youth in low-income communities: A multi-method evaluation. Child and Adolescent Social Work Journal, 23(5-6), 635-652. https://doi.org/10.1007/s10560006-0079-0 